\title{
Effect of formaldehyde inhalation on rabbit nasal mucosa: a light microscopic study — an animal model for inhalational irritants on nasal mucosa
}

\author{
Wael Mohamed Adel AbdelKafy, Reham Farouk Zittoon, Ashraf Saad Abou-Halawa, \\ Ereny Fekry Youssef Makary and Mohamed Rifaat Ahmed
}

\begin{abstract}
Background: Formaldehyde is associated with many adverse health effects and is classified as a human carcinogen. Formaldehyde is highly water-soluble and readily absorbed and metabolized by the respiratory mucosa upon inhalation. The histopathological effects of formaldehyde on the nasal mucosa and olfactory nerves in adult New Zealand white rabbits were studied to validate this animal model of inhalational irritants.

Results: Compared to control group 1 (exposed to air), groups 2 and 3 (exposed to formaldehyde for 90 min and 210 min, respectively) exhibited disrupted nasal tissue, ulcerated epithelial coverings, markedly dilated blood vessels, and increased numbers of inflammatory cells in the lamina propria. The olfactory neuro-epithelium exhibited a reduction in the number of cilia. Many sustentacular cells lost their microvilli. Olfactory nerves exhibited nerve bundle shrinkage within the perineural sheath, leaving an empty space with evidence of edema within the nerve fibers.

Conclusion: Formaldehyde inhalation has destructive effects on the nasal mucosa and olfactory nerves in adult New Zealand white rabbits. These results validate the use of this animal model to assess the effects of inhalational irritants on the nasal mucosa.
\end{abstract}

Keywords: Formaldehyde, Mucosa, Olfactory, Histology, Inhalation

\section{Background}

Formaldehyde is a simple aldehyde that exists as a colorless gas at room temperature and has an acrid characteristic odor. Its half-life in air ranges between $7 \mathrm{~h}$ and 3 days depending on sunlight, temperature, and other environmental conditions [1]. Formalin is a $37 \%$ aqueous solution of formaldehyde that is used as a tissue preservative and an antiseptic [2].

Acute exposure to formaldehyde is associated with respiratory tract inflammation and irritation of the eyes and skin. Long-term formaldehyde exposure at levels commonly found in the environment represents a great

\footnotetext{
*Correspondence: wael.abdelkafy@gmail.com

Faculty of Medicine, Suez Canal University, Ismailia, Egypt
}

concern in the field of environmental public health [3]. Many molecular events are associated with formaldehyde inhalation. Formaldehyde acts as an electrophile and reacts with macromolecules, such as DNA, RNA, and proteins, to form irreversible cross-links [4].

Formaldehyde is considered an animal and human carcinogen and causes nasal squamous cell carcinomas in rats chronically exposed to concentrations of $6 \mathrm{ppm}$ and greater $[5,6]$. In humans, formaldehyde is associated with an increased risk of nasopharyngeal cancer and possibly leukemia $[7,8]$.

Rabbits have been used to study the effect of nasally applied medications $[9,10]$ and are considered good models for rhinological research [11]. The aim of this study was to investigate the histopathological effects of 
formaldehyde inhalation on the nasal mucosa and the olfactory nerves of adult New Zealand white rabbits by light microscopy.

\section{Methods}

This experimental study was conducted in the ENT Department and Histological Unit in the Faculty of Medicine. Approval from the Institutional Animal Care and Use Committee was obtained before starting the study.

Thirty healthy adult New Zealand white male rabbits of the same age (7-10 weeks) and average weight (200 g) were used. The basic criteria for animal selection were normal healthy nasal mucosa with the absence of infection and discharge. Animals in this study were obtained from the veterinary medicine animal house faculty of veterinary medicine.

Animals were randomly assigned into three groups: group $1(n=10)$, control group exposed to normal air for $210 \mathrm{~min}$ at room temperature; group $2(n=10)$, exposed to $3 \mathrm{~g}$ volatilized formaldehyde for $90 \mathrm{~min}$; and group 3 $(n=10)$, exposed to $5 \mathrm{~g}$ of volatilized formaldehyde for $210 \mathrm{~min}$.

Experiments were performed in a room with a $5.5-\mathrm{m}^{3}$ capacity. A large door opening into the room was closed, but no attempt was made to prevent the egress of the formaldehyde or the ingress of air through the keyhole and cracks in the door. Formaldehyde gas was then generated by slowly volatilizing paraformaldehyde pastils in a Schering disinfecting lamp [12]. The lamp was set in the middle of the room, and the animals were placed in a cage near the door.

Each group was maintained in a separate cage and was fed ad libitum for $24 \mathrm{~h}$. Animals were housed under standardized conditions with free access to food and water under strict care and hygiene to maintain animals in normal healthy conditions. The rabbits were then sacrificed with an intraperitoneal injection of $100 \mathrm{mg}$ of sodium pentobarbital followed by a $50-\mathrm{mg}$ intracardiac injection after loss of consciousness if necessary [13]. The nasal mucosa was harvested, and the specimen from each animal was stained using hematoxylin and eosin (H\&E). Histological data from groups 2 and 3 were analyzed and compared with the images from the control group (group 1).

\section{Results}

The control group (group 1) showed normal nasal mucosa with well-organized tissue layers, i.e., uniform pseudostratified columnar epithelial lining, connective tissue overlying lamina propria with scattered uniform blood vessels, and underlying cartilage (Fig. 1). The olfactory neuro-epithelium exhibited a rich mesh of cilia of olfactory receptor cells and microvilli of sustentacular cells. Olfactory nerve fibers exhibited an intact uniform perineural sheath that was filled with uniform nerve bundles (Fig. 2).

Group 2 and group 3 animals exhibited an ulcerated surface epithelium, areas of irregular nasal tissue, and congested blood vessels in the lamina propria. Inflammatory changes were evident in the form of many polymorphonuclear leucocytes, numerous eosinophils, and a few mononuclear leukocytes (Fig. 3). The olfactory neuroepithelium exhibited a reduction in the number of cilia. Many sustentacular cells lost their microvilli. Shrinkage of olfactory nerve bundles was noted within the perineural sheath, leaving an empty space with evidence of edema within the nerve fibers (Fig. 4). All of these histological changes were more obvious in the more exposed animals (group 3) compared with group 2.

\section{Discussion}

The nasal mucosa is the first target of formaldehydeinduced toxic effects. Klipstein was the first to report the

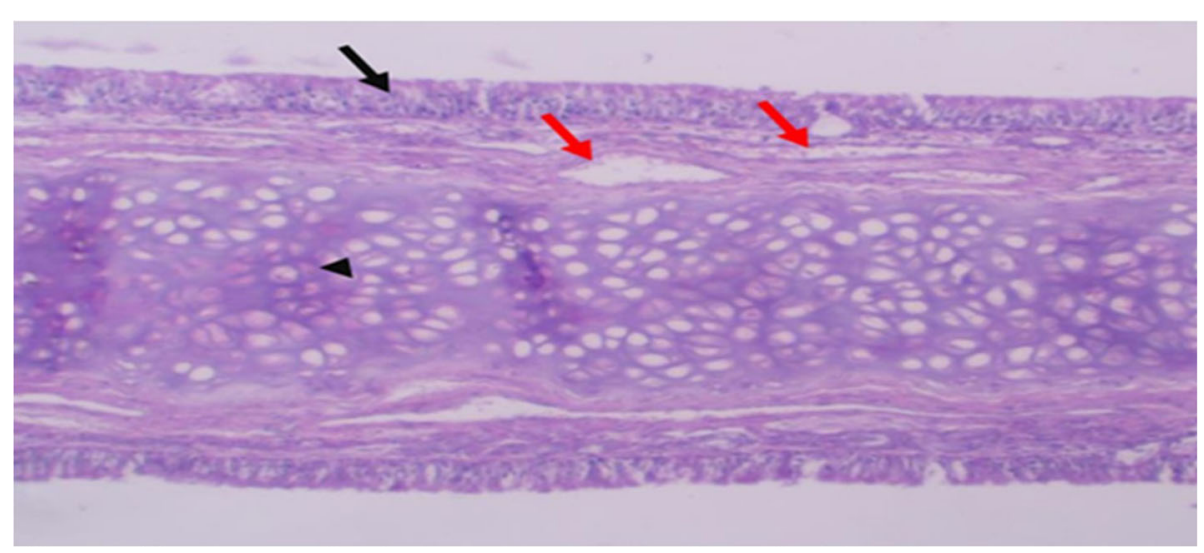

Fig. 1 Nasal mucosa (control group) showing well-organized tissue layers: uniform pseudostratified columnar epithelium (black arrow); overlying connective tissue lamina propria, with scattered uniform blood vessels (red arrows); and underlying cartilage (arrowhead) (H\&E, $\times 10)$ 


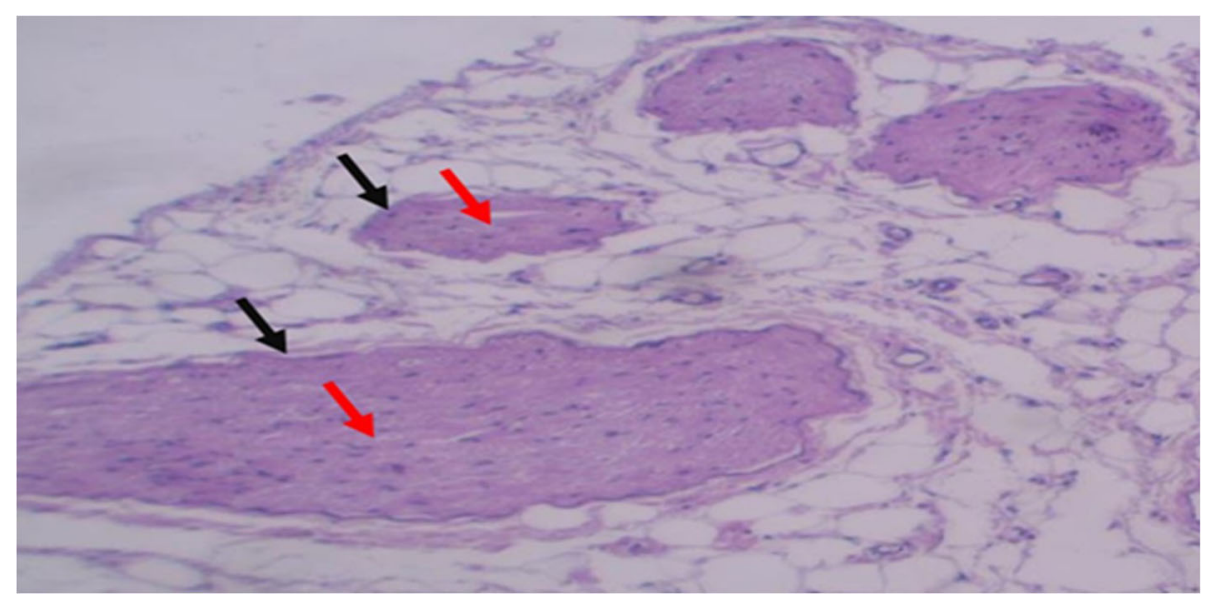

Fig. 2 Olfactory nerve (control group) showing uniform perineural sheath (black arrow) filled with uniform regular nerve bundles (red arrow) $(H \& E, \times 10)$

noxious effects of formaldehyde inhalation in rabbits in 1898 [12]. At high exposure concentrations, formaldehyde is a soluble and reactive gas that is rapidly absorbed by the upper respiratory tract, causes nasal tumors in laboratory animals, and may cause nasopharyngeal cancer in humans. Risk estimates of formaldehyde inhalation in humans must account for the doseresponse behavior at concentrations well below those where effects were observed in animals [14].

Arican et al. studied the effects of formaldehyde inhalation in Wistar rats with light and electron microscopy. These researchers found that it significantly decreased the density of structural proteins of the junctional complex in the nasal mucosa compared to the control group. It also caused thickness of the basal lamina, increased vacuoles in cytoplasmic areas, and irregular forms of kinocilium. At high concentrations, formaldehyde caused hypertrophy of goblet cells, disturbance of tissue integrity, and basal lamina degeneration [15].
Formaldehyde is used in many manufacturing processes, including the production of fertilizer, wood and paper products, and the textile, rubber, and cement industries. In our study, we only investigated the acute changes in the nasal mucosa after exposure to formaldehyde vapor. However, repeated exposure in certain occupations should be considered a real health hazard [16]. The longer the duration, the more marked the pathologic changes in the respiratory mucosa.

Edling et al. studied the cytotoxic effects of occupational exposure of formaldehyde on nasal mucosa in 75 men. Only three of them had normal mucosa; the remainder exhibited loss of cilia, goblet cell hyperplasia, or squamous metaplasia. In six cases (8\%), mild dysplasia was noted [17].

In a controlled study, Sherwani et al. investigated the effect of formaldehyde vapor on the nasal mucosa in 53 students (undergraduates and postgraduates). The nasal mucosa was swabbed, and Papanicolaou and Giemsa

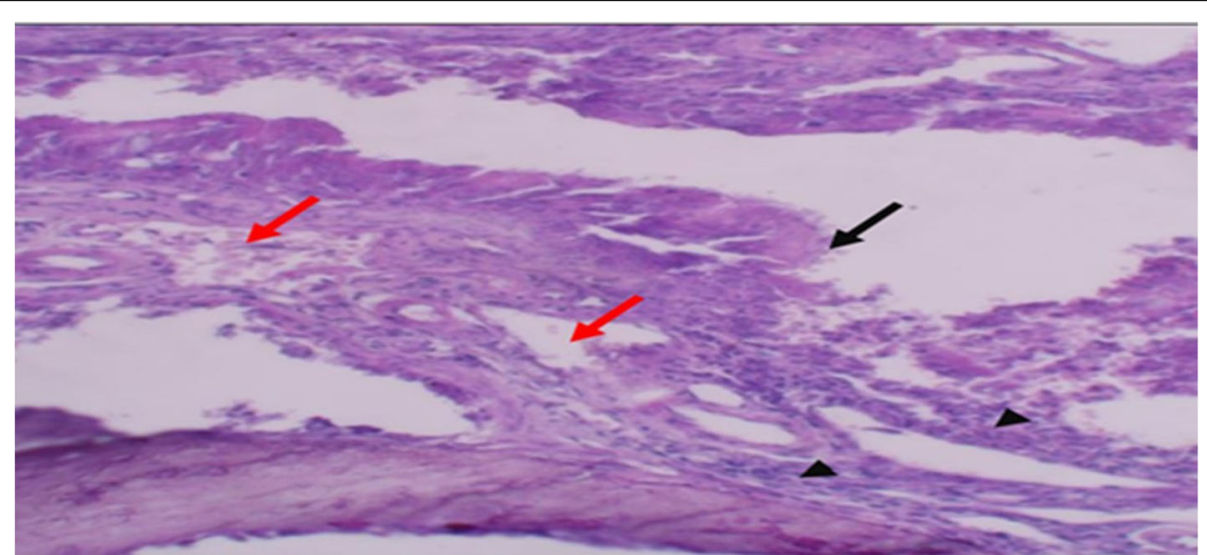

Fig. 3 Nasal mucosa (group 2) characterized by disrupted nasal tissue, ulcerated epithelial covering, markedly dilated blood vessels in the lamina propria (red arrow), and mild inflammatory reaction $(H \& E, \times 10)$ 


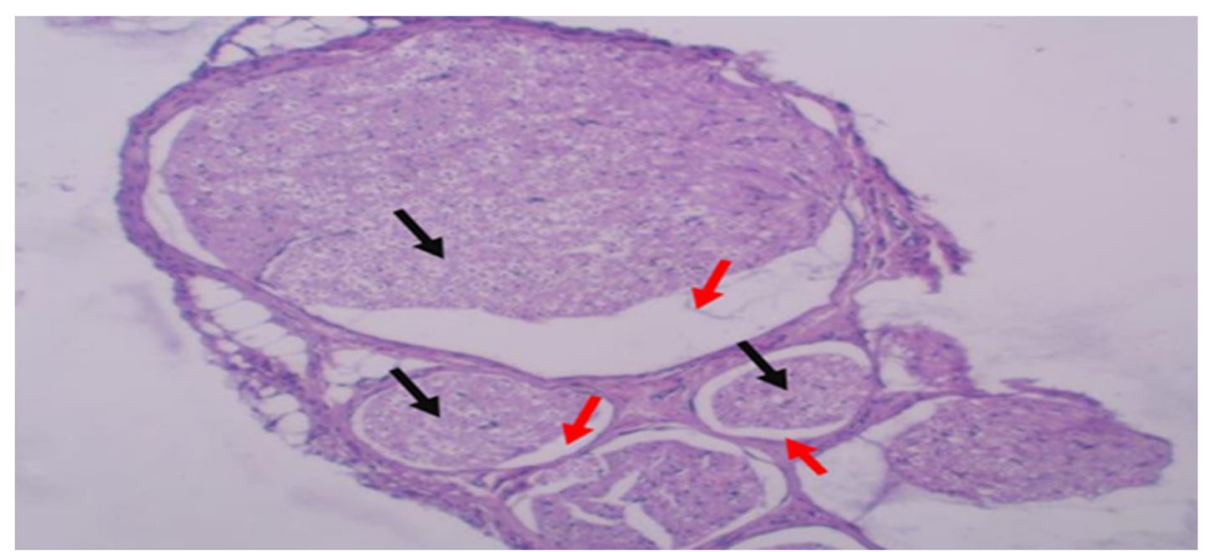

Fig. 4 Olfactory nerve (group 2) showing shrinkage of the nerve bundles within the perineural sheath, leaving empty spaces (red arrow) with evidence of edema within the nerve fibers (black arrow) $(H \& E \times 10)$

stains were used. Marked squamous metaplasia was noted as evidenced by anucleated squamous cells and micronuclei as well as a decrease in goblet cells and columnar cells. Postgraduate students who had a longer duration of exposure to formaldehyde exhibited more changes than undergraduate students [18].

Through our light microscopic experimental study, we would like to draw attention to the acute effects of formaldehyde inhalation on the nasal mucosa. We admit that the use of electron microscopy and cytogenetic analysis would have helped to elucidate the underlying molecular biological changes induced by this noxious gas. These topics may be addressed in our future research.

\section{Conclusion}

Formaldehyde inhalation is destructive to the nasal mucosa and olfactory nerves in adult New Zealand white rabbits as demonstrated by a light microscope. These results validate the use of this animal model to assess the effects of inhalational irritants on the nasal mucosa.

\section{Abbreviations}

DNA: Deoxyribonucleic acid; RNA: Ribonucleic acid; H\&E: hematoxylin and eosin

\section{Acknowledgements}

I would like to extend my sincere gratitude to the histology lab team, Faculty of Medicine, Suez Canal University, for the great help doing all the sample preparations and histological analysis. I would like also to thank my professors and colleagues who participated in this work.

\section{Authors' contributions}

All authors have read and approved the final manuscript. WA: study design, editing of the manuscript, submission process, data collection, and analysis. RZ: lab work, obtaining experimental animals, collection of data, and study design. AH: study design, lab work supervision, and data collection supervision. EM: histological preparations and analysis, data collection, and study design. MA: study design, supervision of the research team, writing and editing of the manuscript, and supervision of data collection.

\section{Funding}

Nothing to declare

\section{Availability of data and materials}

The datasets used and/or analyzed during the current study are available from the corresponding author on reasonable request.

\section{Declarations}

\section{Ethics approval and consent to participate}

This study was conducted in the ENT Department and Histological Unit in the Faculty of Medicine, Suez Canal University. Approval from the Institutional Animal Care and Use Committee was obtained before starting the study.

Committee reference number-not applicable. Consent to participate is not applicable.

\section{Consent for publication}

Not applicable.

\section{Competing interests}

The authors declare that they have no competing interests.

Received: 19 July 2020 Accepted: 12 April 2021

Published online: 03 May 2021

\section{References}

1. Farooqui MY (1983) Formaldehyde. J Appl Toxicol. 3(5):264-265. https://doi. org/10.1002/jat.2550030510

2. Takayasu T (2013) Toxicological analyses of medications and chemicals in formalin-fixed tissues and formalin solutions: a review. J Anal Toxicol. 37(9): 615-621. https://doi.org/10.1093/jat/bkt055

3. IARC Working Group on the Evaluation of Carcinogenic Risks to Humans. Formaldehyde, 2-butoxyethanol and 1-tert-butoxypropan-2-ol. IARC Mongr Eval Carcinog Risks Hum. 2006:88:1-478.

4. Casanova M, Morgan KT, Steinhagen WH, Everitt JI, Popp JA, Heck HD (1991) Covalent binding of inhaled formaldehyde to DNA in the respiratory tract of rhesus monkeys: pharmacokinetics, rat-to-monkey interspecies scaling, and extrapolation to man. Fundam Appl Toxicol. 17(2):409-428. https://doi.org/10.1016/0272-0590(91)90230-2

5. Kerns WD, Pavkov KL, Donofrio DJ, Gralla EJ, Swenberg JA (1983) Carcinogenicity of formaldehyde in rats and mice after long-term inhalation exposure. Cancer Res. 43(9):4382-4392

6. Schroeter JD, Campbell J, Kimbell JS, Conolly RB, Clewell HJ, Andersen ME (2014) Effects of endogenous formaldehyde in nasal tissues on inhaled formaldehyde dosimetry predictions in the rat, monkey, and human nasal passages. Toxicol Sci. 138(2):412-424. https://doi.org/10.1093/toxsci/kft333

7. Sheehan P, Singhal A, Bogen KT, MacIntosh D, Kalmes RM, McCarthy J (2018) Potential exposure and cancer risk from formaldehyde emissions from installed Chinese manufactured laminate flooring. Risk Anal. 38(6): 1128-1142. https://doi.org/10.1111/risa.12926 
8. Lyapina M, Zhelezova G, Petrova E, Boev M (2004) Flow cytometric determination of neutrophil respiratory burst activity in workers exposed to formaldehyde. Int Arch Occup Environ Health. 77(5):335-340. https://doi. org/10.1007/s00420-004-0516-3

9. Bortolotti F, Balducci AG, Sonvico F, Russo P, Colombo G (2009) In vitro permeation of desmopressin across rabbit nasal mucosa from liquid nasal sprays: the enhancing effect of potassium sorbate. Eur J Pharm Sci. 37:36-42

10. Lu HT, Chen RN, Sheu MT, Chang CC, Chou PY, Ho HO (2011) Rapid-onset sildenafil nasal spray carried by microemulsion systems: in vitro evaluation and in vivo pharmacokinetic studies in rabbits. Xenobiotica. 41(7):567-577. https://doi.org/10.3109/00498254.2011.563877

11. Perez AC, Buzatto GP, Dantas Ide P, Dorgam JV, Valera FC, Tamashiro E et al (2014) Review of experimental models: sinusitis in rabbits. Braz J

Otorhinolaryngol. 80(5):435-440. https://doi.org/10.1016/j.bjorl.2014.07.011

12. Fischer MH (1900) The toxic effects of formaldehyde and formalin: (a preliminary communication). J Boston Soc Med Sci. 5(1):18-22

13. Iskander NM, Youssef TF, Ahmed MR, Mohamed AA (2010) Is halofantrine ototoxic? Experimental study on guinea pig cochlea model. J Laryngol Otol. 124(10):1061-1066. https://doi.org/10.1017/S0022215110001301

14. Fischer MH (1905) The toxic effects of formaldehyde and formalin. J Exp Med. 6(4-6):487-518. https://doi.org/10.1084/jem.6.4-6.487

15. Arican RY, Sahin Z, Ustunel I, Sarikcioglu L, Ozdem S, Oguz N (2009) Effects of formaldehyde inhalation on the junctional proteins of nasal respiratory mucosa of rats. Exp Toxicol Pathol. 61(4):297-305. https://doi.org/10.1016/j. etp.2008.09.005

16. Chang JC, Gross EA, Swenberg JA, Barrow CS (1983) Nasal cavity deposition, histopathology, and cell proliferation after single or repeated formaldehyde exposures in B6C3F1 mice and F-344 rats. Toxicol Appl Pharmacol. 68(2): 161-176. https://doi.org/10.1016/0041-008X(83)90001-7

17. Edling C, Hellquist H, Odkvist L (1988) Occupational exposure to formaldehyde and histopathological changes in the nasal mucosa. Br J Ind Med. 45:761-765

18. Sherwani R, Siddiqui RA, Khan MK, Sharma SC (2002) Nasal mucosa changes in students exposed to formaldehyde vapour. Indian J Otolaryngol Head Neck Surg. 54(1):18-19. https://doi.org/10.1007/BF02910999

\section{Publisher's Note}

Springer Nature remains neutral with regard to jurisdictional claims in published maps and institutional affiliations.

\section{Submit your manuscript to a SpringerOpen ${ }^{\circ}$ journal and benefit from:}

- Convenient online submission

- Rigorous peer review

- Open access: articles freely available online

- High visibility within the field

- Retaining the copyright to your article

Submit your next manuscript at $\boldsymbol{\nabla}$ springeropen.com 